\title{
LYAPUNOV-TYPE INEQUALITIES FOR FRACTIONAL DIFFERENTIAL EQUATIONS UNDER MULTI-POINT BOUNDARY CONDITIONS
}

\author{
YOUYU WANG AND QICHAO WANG
}

Abstract. In this work, we establish new Lyapunov-type inequalities for fractional differential equations under multi-point boundary conditions.

Mathematics subject classification (2010): 34A40, 26A33, 34B05.

Keywords and phrases: Lyapunov inequality, fractional differential equation, multi-point boundary value problem, Green's function.

\section{REFERENCES}

[1] R. C. BRown, D. B. Hinton, Lyapunov inequalities and their applications, in Survey on Classical Inequalities, T. M. Rassias, Ed. Kluwer Academic Publishers, Dordrecht, The Netherlands, 2000, 125.

[2] I. CABRera, K. SAdARANGANi AND B. SAmet, Hartman-Wintner-type inequalities for a class of nonlocal fractional boundary value problems, Math. Meth. Appl. Sci., 40, (2017) 129-136.

[3] S. Cheng, Lyapunov inequalities for differential and difference equations, Fasc. Math. 23 (1991) $25-41$.

[4] R. A. C. Ferreira, A Lyapunov-type inequality for a fractional boundary value problem, Fract. Calc. Appl. Anal. 16, No 4 (2013), 978-984.

[5] R. A. C. Ferreira, On a Lyapunov-type inequality and the zeros of a certain Mittag-Leffler function, J. Math. Anal. Appl. 412, No 2 (2014), 1058-1063.

[6] M. JLELI AND B. S AMET, Lyapunov-type inequalities for a fractional differential equation with mixed boundary conditions, Math. Inequal. Appl. 18, No 2 (2015), 443-451.

[7] M. JLELI, L. RAGOUB AND B. SAMET, Lyapunov-type inequality for a fractional differential equation under a Robin boundary conditions, J. Func. Spaces. 2015, Article ID 468536, 5 pages.

[8] A. A. Kilbas, H. M. SRivastava And J. J. Trujillo, Theory and applications of fractional differential equations, North-Holland Mathematics Studies 204 Elsevier, Amsterdam, The Netherlands, 2006.

[9] A. M. Lyapunov, Probleme gé $n$ é ral de la stabilité du mouvement, (French Translation of a Russian paper dated 1893), Ann. Fac. Sci. Univ. Toulouse 2 (1907)27-247 (Reprinted as Ann. Math. Studies, No. 17, Princeton Univ. Press, Princeton, NJ, USA, 1947).

[10] D. O'REGAN, B. SAMET, Lyapunov-type inequalities for a class of fractional differential equations, Journal of Inequalities and Applications, 2015 2015(247):1-10.

[11] J. Rong, C. BAI, Lyapunov-type inequality for a fractional differential equation with fractional boundary conditions, Advances in Difference Equations 20152015 (82): 1-10.

[12] A. TIRYAKI, Recent development of Lyapunov-type inequalities, Adv. Dyn. Syst. Appl., 5 No 2 (2010), 231-248.

[13] Y. WANG, S. LIANG AND C. XIA, A Lyapunov-type inequality for a fractional differential equation under Sturm-Liouville boundary conditions, Math. Inequal. Appl., 20 No 1 (2017), 139-148. 